\title{
Pengaruh Kepemimpinan dan Motivasi terhadap Kinerja Karyawan PDAM Tirta Musi Unit Sako Kenten
}

\author{
M. Hafis Erlangga ${ }^{1)}$ \\ 1) PDAM Tirta Musi, Palembang \\ Email: hafis.erlanggaa11@gmail.com ${ }^{1)}$
}

\begin{abstract}
This study aims to examine the influence of leadership and motivation on the performance of employees of PDAM Tirta Musi Unit Sako Kenten. Sources of data obtained through observation, document study, interviews and questionnaires to all 42 respondents. The results of the study indicates that leadership (X1) has a significant partial effect on the performance variable (Y). Then the results of the study indicate motivation (X2) has a significant partial effect on performance $(\mathrm{Y})$. This research is expected to provide benefits to the company in terms of improving employee performance.
\end{abstract}

Keywords: Leadership, Motivation, Employee Performance

\begin{abstract}
Abstrak
Penelitian ini bertujuan untuk meneliti pengaruh kepemimpinan dan motivasi terhadap kinerja karyawan PDAM Tirta Musi Unit Sako Kenten. Sumber data yang diperoleh melalui observasi, studi dokumen, wawancara dan penyebaran kuesioner kepada seluruh anggota 42 responden. Hasil penelitian secara parsial menunjukkan bahwa kepemimpinan (X1) berpengaruh signifikan terhadap variabel kinerja (Y). Kemudian hasil penelitian secara parsial menunjukkan variable motivasi (X2) berpengaruh signifikan terhadap kinerja (Y). Penelitian ini diharapkan dapat memberikan manfaat kepada perusahaan dalam hal meningkatkan kinerja karyawan Kata Kunci: kepemimpinan, motivasi, kinerja karyawan.
\end{abstract}

Kata Kunci: Kepemimpinan, Motivasi, Kinerja Karyawan

\section{Pendahuluan}

\subsection{Latar Belakang}

PDAM Tirta Musi Palembang merupakan salah satu perusahaan milik daerah di kota Palembang yang menyediakan air bersih khusus bagi masyarakat kota Palembang. Perusahaan Daerah Air Minum Tirta Musi Palembang mempunyai visi untuk menjadi penyedia air minum terbaik di Indonesia melalui pelayanan prima serta menjadi kebanggaan karyawan dan masyarkat. Dari visi ini, terlihat jelas bahwa untuk mewujudkan itu semua PDAM Tirta Musi harus mempunyai sumber daya manusia yang berkualitatas. Sumber daya manusia yang berkulitas bisa diwujudkan oleh PDAM Tirta Musi apabila perusahaan tersebut mampu memberikan kepemimpinan serta motivasi kerja yang tepat bagi karyawannya agar bisa secara terus menerus mengembangkan kemampuan karyawan dalam mencapai tujuan yang diinginkan perusahaan.

Adanya pergantian pimpinan pada PDAM Tirta Musi khususnya Unit Pelayanan Sako Kenten berakibat terjadinya penurunan semangat kerja dari karyawan, yang diduga karena perubahan pola kepemimpinan mulai dari prosedur yang berubah, kurangnya motivasi yang diberikan oleh perusahaan terhadap karyawan dalam menjalankan tugas, serta ada kecanggungan dalam hal komunikasi antara pimpinan baru dengan karyawan. Hal ini jika dibiarkan akan berdampak 
pada penurunan kinerja karyawan pada PDAM Tirta Musi itu sendiri.

\subsection{Perumusan Masalah}

Berdasarkan latar belakang yang telah di uraikan diatas, maka penulis merumuskan masalah sebagai berikut :

1. Apakah kepemimpinan berpengaruh secara parsial terhadap kinerja karyawan PDAM Tirta Musi Unit Sako Kenten?

2. Apakah motivasi kerja berpengaruh secara parsial terhadap kinerja karyawan PDAM Tirta Musi Unit Sako Kenten?

3. Apakah kepemimpinan dan motivasi kerja berpengaruh secara simultan terhadap kinerja karyawan PDAM Tirta Musi Unit Sako Kenten ?

\subsection{Tujuan Penelitian}

Adapun tujuan dari penelitian ini adalah :

1. Untuk mengetahui pengaruh kepemimpinan secara parsial terhadap kinerja karyawan PDAM Tirta Musi Unit Sako Kenten.

2. Untuk mengetahui pengaruh motivasi kerja secara parsial terhadap kinerja karyawan PDAM Tirta Musi Unit Sako Kenten.

3. Untuk mengetahui pengaruh kepemimpinan dan motivasi kerja secara simultan terhadap kinerja karyawan PDAM Tirta Musi Unit Sako Kenten.

\section{Tinjauan Pustaka}

Dalam penelitian ini, penulis akan membahas tentang teori-teori yang berhubungan dengan kepemimpinan dan motivasi terhadap kinerja karyawan.

\subsection{Pengertian Kepemimpinan}

Menurut Thoha (Busro, 2017) kepemimpinan adalah cara yang digunakan seorang pemimpin dalam memengaruhi bawahan agar mau melaksanakan tugas dan kewajibannya sesuai dengan yang diharapkan agar tercapai tujuan yang telah ditentukan sebelumnya.

\subsection{Indikator Kepemimpinan}

Beberapa indikator dari variabel kepemimpinan menurut Ivancevich, Konopaske, dan Matteson (Busro, 2017) adalah sebagai berikut :

\section{Telling}

Kemampuan dalam membuat aturan yang diperlukan untuk mengerjakan pekerjaan, dan menceritakan kepada karyawan tentang apa, siapa, dimana, bagaimana, kapan, dan mengapa harus mengerjakan tugas.

\section{Selling}

Menyangkut langkah pemimpin memerintah karyawan dengan perintah terstruktur dan harus dilakukan secara suportif.

\section{Participating}

Pemimpin dan karyawan bekerja sama dalam membuat dan menjalankan keputusan yang telah ditetapkan untuk mencapai kualitas kerja yang baik. 


\section{Delegating}

Pemimpin memberikan arahan mengenai sesuatu secara spesifik, dan mendelegasikan kepada karyawan untuk melaksanakan tugas sesuai arahan.

\subsection{Pengertian Motivasi}

Menurut Robbins dan Coulter (Sumardjo dan Priansa, 2018) menyatakan bahwa motivasi adalah kesediaan untuk melaksanakan perintah, untuk mencapai tujuan-tujuan keorganisasian yang dilakukan sesuai dengan kemampuan individual tertentu.

\subsection{Indikator Motivasi}

Menurut Masllow (Busro, 2017) ada beberapa indikator yang memengaruhi motivasi, yaitu:

1. Kebutuhan Fisiologi

Kebutuhan utama individu dalam mempertahankan hidupnya yang meliputi kebutuhan akan makan, minum, pakaian dan tempat tinggal.

2. Kebutuhan Keselamatan

Kebutuhan ini antara lain kebutuhan akan perlindungan dari ancaman dan pertentangan.

3. Kebutuhan Sosial

Kebutuhan untuk diterima oleh kelompok, berafiliasi, berinteraksi dengan sesama.

4. Kebutuhan Penghargaan Diri

Kebutuhan untuk dihormati dan dihargai oleh orang lain

5. Kebutuhan Aktualisasi Diri

Kebutuhan untuk menggunakan kemampuan, skill, dan potensi. Kebutuhan untuk berpendapat dengan mengemukakan ide-ide, gagasan, dan kritik terhadap sesuatu.

\subsection{Pengertian Kinerja Karyawan}

Menurut Busro (2017) kinerja merupakan hasil kerja yang dapat dicapai karyawan baik individu maupun kelompok dalam suatu organisasi, sesuai dengan wewenang dan tanggung jawab yang diberikan organisasi dalam upaya mencapai visi, misi, dan tujuan organisasi bersangkutan dengan menyertakan kemampuan, ketekunan, kemandirian, kemampuan mengatasi masalah sesuai batas waktu yang diberikan secara legal, tidak melanggar hukum dan sesuai dengan moral maupun etika.

\subsection{Indikator Kinerja Karyawan}

Indikator kinerja karyawan menurut Mathis dan Jackson, (Safitri :2016) adalah sebagai berikut:

1. Kuantitas

2. Kualitas

3. Ketepatan Waktu

4. Kehadiran

5. Kemampuan Bekerja Sama

\section{Metode Penelitian}




\subsection{Ruang Lingkup Penelitian}

Dalam penelitian ini akan membahas masalah yang berkaitan dengan Pengaruh Kepemimpinan Dan Motivasi Terhadap Kinerja Karyawan PDAM Tirta Musi Unit Sako Kenten.

\subsection{Populasi \& Sampel}

Populasi dan Sampel yang digunakan dalam penelitian ini adalah sebagai berikut:

1. Populasi yang digunakan adalah semua karyawan PDAM Tirta Musi Unit Sako Kenten yang berjumlah 42 orang.

2. Teknik sampel yang digunakan adalah sampling jenuh, dengan menjadikan semua anggota populasi menjadi sampel penelitian. Berdasarkan teknik tersebut, jumlah sampel yang digunakan dalam penelitian ini adalah 42 orang responden.

\section{Hasil dan Diskusi}

Berdasarkan kuesioner yang dibagikan kepada responden, berikut ini akan dilakukan pembahasan yang bertujuan untuk membahas masalah penelitian dan menjawab tujuan penelitian. Responden merupakan seluruh karyawan pada PDAM Tirta Musi Unit Sako Kenten dengan jumlah sebanyak 42 orang dan pengelolaan data menggunakan bantuan SPSS V.20 for windows maka didapatkan penelitian sebagai berikut :

\subsection{Uji Validitas}

Menurut Sujarweni (2018) data yang diperoleh dari kuisioner kemudian dilakukan uji validitas dengan melihat korelasi antar item pertanyaan. Jika $r$ hitung $>r$ tabel, maka data dapat dikatakan valid. Uji validitas digunakan untuk mengetahui kelayakan butir-butir dalam suatu daftar pertanyaan dalam mendefinisikan suatu variabel.

\subsection{Uji Reabilitas}

Menurut Sujarweni (2018) uji realibilitas merupakan suatu ukuran kestabilan dan konsistensi responden dalam menjawab hal yang berkaitan dengan kontruk-kontruk pertanyaan yang merupakan dimensi suatu variabel dan disusun dalam suatu bentuk kuesioner. Uji reliabilitas dapat dilakukan secara bersama-sama terhadap seluruh butir pertanyaan, jika nilai Alpha $>0,6$ maka reliabel, menunjukan tingkat konsistensi dan akurasi hasil pengukuran.

Tabel 1. Hasil Uji Realibilitas

\begin{tabular}{|c|c|c|c|}
\hline Variabel & Cronchbach's Alpha & Ketentuan R $\mathbf{R}_{\text {tabel }}$ & Hasil \\
\hline Kepemimpinan & 0.886 & 0.6 & Reliabel \\
\hline Motivasi & 0.775 & 0.6 & Reliabel \\
\hline Kinerja & 0.769 & 0.6 & Reliabel \\
\hline
\end{tabular}

Hasil uji reliabilitas tersebut menunjukan semua variabel mempunyai koefisien alpha yang cukup besar yaitu diatas 0,6 sehingga dapat dikatakan semua konsep pengukuran masingmasing variabel dari kuisoner reliabilitas sehingga untuk selanjutnya item-item pada masingmasing konsep variabel tersebut layak digunakan sebagai alat ukur.

\subsection{Uji T}


Uji T merupakan metode pengujian dalam statistik yang digunakan untuk menguji besarnnya pengaruh variabel bebas secara parsial terhadap variabel terikat (Sugiyono, 2017).

a. $\quad$ Pengaruh Kepemimpinan (X1) Terhadap Kinerja Karyawan (Y)

Berdasarkan hasil uji $\mathrm{T}$ pada variabel kepemimpinan diperoleh nilai $\mathrm{T}_{\text {hitung }}$ sebesar 3,647 $>\mathrm{T}_{\text {tabel }}$ 2,021 serta terdapat pada tingkat sig sebesar $0,001<0,05$. Dari hasil tersebut dapat disimpulkan bahwa untuk H1 bisa dikatakan bahwa secara parsial Kepemimpinan berpengaruh positif secara signifikan terhadap kinerja karyawan PDAM Tirta Musi Unit Sako Kenten.

b. Pengaruh Motivasi (X2) Terhadap Kinerja Karyawan (Y)

Berdasarkan hasil uji $\mathrm{T}$ pada variabel kepemimpinan diperoleh nilai $\mathrm{T}_{\text {hitung }}$ sebesar 3,196 $>\mathrm{T}_{\text {tabel }}$ 2,021 serta terdapat pada tingkat sig sebesar $0,003<0,05$. Dari hasil tersebut dapat disimpulkan bahwa untuk $\mathrm{H} 2$ bisa dikatakan bahwa secara parsial motivasi berpengaruh positif secara signifikan terhadap kinerja karyawan.

\subsection{Uji F}

Uji F merupakan metode pengujian dalam statistic yang digunakan untuk menguji besarnya pengaruh semua variabel bebas secara bersama-sama terhadap variabel terikat (Sugiyono, 2017).

Berdasarkan hasil pengujian menunjukkan bahwa sig $F$ sebesar $0,002<0,05$ dan $F_{\text {hitung }}$ sebesar 7,312 lebih besar dari $\mathrm{F}_{\text {tabel }}$ sebesar 3,22 (7,312 > 3,22) maka dapat dinyatakan bahwa $\mathrm{H}_{3}$ diterima. Dengan demikian dapat disimpulkan bahwa terdapat pengaruh Kepemimpinan dan Motivasi terhadap Kinerja Karyawan PDAM Tirta Musi Unit Sako Kenten.

\subsection{Analisis Regresi Linear Berganda}

Coefficients $^{\mathrm{a}}$

\begin{tabular}{|c|c|c|c|c|c|c|}
\hline \multirow{2}{*}{\multicolumn{2}{|c|}{ Model }} & \multicolumn{2}{|c|}{$\begin{array}{l}\text { Unstandardized } \\
\text { Coefficients }\end{array}$} & \multirow{2}{*}{$\begin{array}{c}\begin{array}{c}\text { Standardized } \\
\text { Coefficients }\end{array} \\
\text { Beta }\end{array}$} & \multirow[t]{2}{*}{$\mathrm{t}$} & \multirow[t]{2}{*}{ Sig. } \\
\hline & & $\mathrm{B}$ & Std. Error & & & \\
\hline \multirow{3}{*}{1} & (Constant) & 24,666 & 6,362 & & 3,877 & 000 \\
\hline & Kepemimpinan &, 307 & , 159 &, 359 & 1,927 & 061 \\
\hline & Motivasi & ,210 &, 189 & ,207 & 1,115 & ,272 \\
\hline
\end{tabular}

a. Dependent Variable: Kinerja

Berdasarkan tabel diatas besarnya koefisien regresi (B) variabel Kepemimpinan (X1) dan Motivasi (X2) mempunyai nilai koefisien regresi positif, maka dapat dijelaskan bahwa koefisien dengan nilai positif berarti bahwa Kepemimpinan (X1) dan Motivasi (X2) mempunyai pengaruh searah terhadap Kinerja Karyawan (Y).

Konstanta sebesar 24,666 artinya jika tidak ada peningkatan variabel Kepemimpinan (X1) dan Motivasi (X2), maka Kinerja Karyawan (Y) tetap sebesar 24,666. Sedangkan dengan melihat 
besarnya koefisien regresi bahwa variabel Kepemimpinan (X1) sebesar 0,307 dan Motivasi (X2) sebesar 0,210 artinya setiap perubahan atau peningkatan variabel Kepemimpinan (X1) dan Motivasi (X2) sebesar 100\% maka mengakibatkan peningkatan pula pada variabel Kinerja Karyawan sebesar 30,7\% untuk variabel Kepemimpinan (X1) dan 21,0\% untuk variabel Motivasi (X2).

\subsection{Koefisien Korelasi $R$}

\section{Model Summary}

\begin{tabular}{|l|c|r|r|r|}
\hline Model & $\mathrm{R}$ & $\begin{array}{c}\mathrm{R} \\
\text { Square }\end{array}$ & $\begin{array}{r}\text { Adjusted } \\
\text { R Square }\end{array}$ & $\begin{array}{r}\text { Std. Error } \\
\text { of the } \\
\text { Estimate }\end{array}$ \\
\hline 1 &, $522^{\mathrm{a}}$ &, 273 &, 235 & 2,504 \\
\hline
\end{tabular}

a. Predictors: (Constant), Motivasi, Kepemimpinan

Hasil penelitian dengan menggunakan analisis Koefisien korelasi (R) diperoleh nilai sebesar 0,522 . Jadi dapat disimpulkan terdapat hubungan yang terkategori sedang antara variabel kepemimpinan dan motivasi terhadap kinerja karyawan PDAM Tirta Musi Unit Sako Kenten sebesar $52,2 \%$.

\subsection{Koefisien Determinasi $\mathrm{R}^{2}$}

\section{Model Summary}

\begin{tabular}{|l|c|r|r|r|}
\hline Model & $\mathrm{R}$ & $\begin{array}{c}\mathrm{R} \\
\text { Square }\end{array}$ & $\begin{array}{r}\text { Adjusted } \\
\mathrm{R} \text { Square }\end{array}$ & $\begin{array}{r}\text { Std. Error } \\
\text { of the } \\
\text { Estimate }\end{array}$ \\
\hline 1 &, $522^{\mathrm{a}}$ &, 273 &, 235 & 2,504 \\
\hline
\end{tabular}

a. Predictors: (Constant), Motivasi, Kepemimpinan

Hasil penelitian dengan menggunakan analisis Koefisien Determinasi $\left(\mathrm{R}^{2}\right)$ adalah sebesar 0,273 . Hal ini menunjukan besarnya kontribusi variabel Kepemimpinan (X1) dan Motivasi (X2) bisa menjelaskan variabel Kinerja Karyawan (Y) sebesar 27,3\% sedangkan sisanya sebesar $72,7 \%$ bisa dipengaruhi oleh variabel lain yang tidak di masukkan dalam penelitian ini.

\section{Kesimpulan dan Saran}

\subsection{Kesimpulan}

Berdasarkan hasil temuan dalam penelitian ini, maka kesimpulan yang dapat dikemukakan berdasarkan analisis data dan pembahasan yang telah diuraikan, maka dapat di tarik kesimpulan sebagai berikut :

1. Hasil penelitian dengan menggunakan uji t pada variabel Kepemimpinan (X1) diperoleh nilai $\mathrm{T}_{\text {hitung }}>\mathrm{T}_{\text {tabel }}(3,647>2,021)$ dan taraf signifikan $<0,05(0,001<0,05)$, dan variabel Motivasi (X2) diperoleh nilai $\mathrm{T}_{\text {hitung }}>\mathrm{T}_{\text {tabel }}(3,196>2,021)$ dan nilai taraf 
signifikan $<0,05(0,003<0,05)$. Jadi dapat disimpulkan variabel Kepemimpinan dan variabel Motivasi berpengaruh positif dan signifikan terhadap Kinerja karyawan PDAM Tirta Musi Unit Sako Kenten.

2. Hasil analisis Regresi Linier Berganda di peroleh persamaan Regresi $\mathrm{Y}=24,666+$ $0,307 \mathrm{X} 1+0,210 \mathrm{X} 2$, Konstanta sebesar 24,666 artinya jika tidak ada peningkatan variabel Kepemimpinan (X1) dan Motivasi (X2), maka Kinerja Karyawan (Y) tetap sebesar 24,666. Sedangkan dengan melihat besarnya koefisien regresi bahwa variabel Kepemimpinan (X1) sebesar 0,307 dan Motivasi (X2) sebesar 0,210 artinya setiap perubahan atau peningkatan variabel Kepemimpinan (X1) dan Motivasi (X2) sebesar $100 \%$ maka mengakibatkan peningkatan pula pada variabel Kinerja Karyawan sebesar 30,7 \% untuk variabel Kepemipinan (X1) dan 21,0 \% untuk variabel Motivasi (X2).

3. Hasil penilaian dengan menggunakan analisis koefisien Korelasi (R) diperoleh nilai sebesar 0,522. Jadi dapat disimpulkan terdapat hubungan yang terkategori sedang antara variabel Kepemimpinan dan Motivasi terhadap Kinerja Karyawan PDAM Tirta Musi Unit Sako Kenten sebesar $(52,2 \%)$.

4. Hasil penelitian dengan menggunakan analisis Koefisien Determinasi $\left(\mathrm{R}^{2}\right)$ adalah sebesar 0,273. Hal ini menunjukkan besarnya kontribusi variabel Kepemimpinan (X1) dan Motivasi (X2) bisa menjelaskan variabel Kinerja Karyawan (Y) sebesar 27,3\% sedangkan sisanya $72,7 \%$ bisa dijelaskan atau dipengaruhi oleh variabel lain yang tidak di masukkan dalam penelitian ini.

\subsection{Saran}

1. Dari segi kepemimpinan, pimpinan harus meningkatkan terciptanya hubungan yang harmonis dengan karyawan, dan berupaya semaksimal mungkin memberikan motivasi serta dorongan kepada karyawan.

2. Sedangkan dari segi motivasi, pimpinan harus memberikan dorongan yang lebih banyak lagi kepada karyawan agar dapat membangkitkan motivasi kerja karyawan, seperti dengan memberikan bonus dan intensif bagi karyawan yang berprestasi dan teladan. Oleh karena itu, perusahaan harus mampu memperhatikan kedua hal tersebut, karena akan memengaruhi kinerja karyawan pada perushaan.

3. Penelitian ini memberikan informasi bahwa terdapat pengaruh antara kepemimpinan dan motivasi terhadap kinerja karyawan. Selain kepemimpinan dan motivasi, masih terdapat banyak faktor lain yang berhubungan dengan kinerja karyawan yang optimal. Oleh karena itu, disarankan bagi peneliti selanjutnya untuk melakukan penelitian lebih lanjut tentang faktor lain yang memengaruhi kinerja karyawan selain kepemimpinan dan motivasi.

\section{Referensi}

Aprinawati. 2016. Pengaruh Kepemimpinan dan Motivasi Terhadap Kinerja Karyawan PT.

Perkebunan Nusantara IV. Jurnal Plans, Volume 11 No.1.Jurnal PLANS: PenelitianIlmuManajemendanBisnis

Baharuddin, S dan Salam, R. 2020. Pengaruh Kepemimpinan Dan Motivasi Terhadap Kinerja Karyawan Pada PT. Niaga Bangun Persada Di Jakarta. Jurnal Ilmiah, Manajemen Sumber Daya Manusia, Vol. 4, No. 1. 
Busro, Muhammad. 2017. Teori-teori Manajemen Sumber Daya Manusia. Jakarta: Prenadamedia Group.

Farchan, F. 2016. Teknikal Manajemen Sumber Daya Manusia Strategik Sebuah Paradigma Pengukuran Kinerja. Jurnal Pendidikan dan Studi Islam, Vol 1, Desember 2016.

Hidayat, Dayat. 2020. Pengaruh Kepemimpinan Dan Motivasi Terhadap Kinerja Karyawan Pada PT Agung Abadi Di Jakarta. Jurnal Ilmiah, Manajemen Sumber Daya Manusia, Vol. 4, No. 1.

Hersona GW, Sonny. 2017.Pengaruh Kepemimpinan dan Motivasi Terhadap Kinerja KaryawanPT. Post Energy Indonesia. Jurnal of Management and Business, Vol.2

Inaray, Jelita Caroline\& Nelwan, Olivia S dan Lengkong, Victor P.K. 2016. Pengaruh Kepemimpinan dan Motivasi Terhadap Kinerja Karyawan Pada PT. Amanah Finance di Manado.Jurnal Berkata Ilmiah Efisiensi, Vol.16, No.2.

Kbbi.web.id

Kemby, Faya Ester. Tewal, Bernhard, dan Walangitan, Mac Donald. 2017. Pengaruh Kepemimpinan dan Motivasi Terhadap Kinerja Karyawan Pada BP2RD Provinsi Sulawesi Utara. Jurnal EMBA, Vol.5, No.3.

Kurniasari, Rani. 2018. Pemberian Motivasi Serta Dampaknya Terhadap Kinerja Karyawan Pada Perusahaan Telekomunikasi Jakarta. Widya Cipta, Vol II, No.1.

Mulyono, Hardi. 2019. Pengaruh Kepemimpinan dan Motivasi Terhadap Kinerja KaryawanPT Roxy Prameswari Lubuklinggau. Menara Ekonomi, Volume V, No.2.

Permana, Rizky Bayu dan Hermanto, Ahmad. 2020. Pengaruh Kepemimpinan dan Motivasi Terhadap Kinerja Karyawan PT. Cipta Niaga Semesta. Jurnal Ekonomi dan Industri, Volume 21, No.1

Prasetiyani, Desi. 2020. Pengaruh Kepemimpinan dan Motivasi Terhadap Kinerja Karyawan Pada PT. Surya Barutama Balaraja. Jurnal Manajemen dan Akuntansi, Volume 15 Nomor 2

Rolos, J.J.R, Sambul, S.A.P, dan Rumawas, W. 2018. Pengaruh Beban Kerja Terhadap Kinerja Karyawan Pada PT. Asuransi Jiwasraya Cabang Manado Kota. Jurnal Administrasi Bisnis, Vol. 6 No. 4.

Safitri, Ria Prasetya. 2018. Pengaruh Budaya Perusahaan Terhadap Motivasi Kerja dan Dampaknya Pada Kinerja Karyawan. Journal of management, Vol 2, No.2

Sari, R.N.I, dan Hadijah, H.S. 2016. Peningkatan Kinerja Pegawai Melalui Kepuasan Kerja dan Disiplin Kerja. Jurnal Pendidikan Manajemen Perkantoran, Vol. 1 No. 1.

Siregar, Sofyan. 2017. Statistika Deskriptif. Bandung: Raja Grafindo Persada.

Sugiyono. 2017. Metodelogi Penelitian Kualitatif, Kuantitatif dan R\&D. Bandung: Alfabeta.

Sujarweni. 2018. Metodelogi Penelitian. Yogyakarta: PT Fajar Interpratama Mandiri.

Sumardjo, M dan Priansa, J.P.2018. Manajemen Pengembangan Sumber Daya Manusia. Bandung: Alfabeta.

Suswanto. 2020. Pengaruh Kepemimpinan dan Motivasi Terhadap Kinerja Karyawan Pada Koperasi Bmt El-Raushan Tanggerang. Jenius, Vol.3, No.2. 
Tho'in, Muhammad. 2016. Kompetensi Sumber Daya Manusia Bank Syariah Berdasarkan Prinsip-Prinsip Syariah Islam. Jurnal Ilmiah Ekonomi Islam, Vol 2 No. 3.

Wahyudi, A. S. 2016. Kinerja Karyawan Ditinjau Dari Gaya Kepemimpinan dan Sistem Upah Kerja Pada PT Safari Salatiga. Surakarta: Universitas Muhammadiyah.

Wijayanti, Dwi Wahyu. 2012. Pengaruh Kepemimpinan Dan Motivasi Kerja Terhadap Kinerja Karyawan Pada PT. Daya Anugerah Semesta Semarang. Semarang: Universitas Negeri Semarang.

www.tirtamusi.com

Yuliati, E.2020. Pengembangan Sumber Daya Manusia Berbasis Total Quality Management di SMK Muhammadiyah Prambanan. Jurnal Manajemen Pendidikan Islam, Vol. 04 No.01. 